ITEJ Juli-2019, Volume 4 Nomor 1 Page 52 - 66

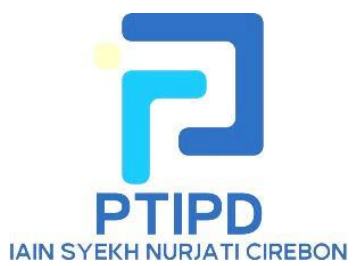

ITEJ
Information Technology Engineering Journals
eISSN : $2548-2157$

Url : https://syekhnurjati.ac.id/journal/index.php/itej

Email : itej@syekhnurjati.ac.id

\title{
Internet of Things Technology Development
}

\author{
Amy Sulastri \\ STMIK Kediri \\ Jurusan Teknik Informatika \\ amy_sulastri09@gmail.com
}

\begin{abstract}
The Internet of Things (IoT) refers to the existence of physical devices that are interconnected and widely identified. The purpose of these devices is to collect data and encourage actions to increase productivity, and ultimately reduce or eliminate dependence on human intervention for data acquisition, interpretation, and use. IoT devices can be sensors or actuators. This survey paper aims to gather and summarize some of the most recent library resources on the Internet of Things (IoT) devices. From the results of the paper survey, IoT devices can be grouped into twelve categories, namely: temperature, pressure, flow, level, imaging, noise, air pollution, proximity and displacement, infrared, moisture and humidity, speed, gas and chemical.
\end{abstract}

Keywords—Internet of Things (IoT), IoT Devices, Sensors, Actuators, Survey Paper

\section{INTRODUCTION}

Internet of things(IoT) has emerged as the next big thing on the Internet. It is estimated that billions of physical objects will be equipped with various types of sensors and actuators and be connected to the internet through heterogeneous access networks made possible by technologies such as sensing and embedded movement, radio frequency identification (RFID), wireless sensor networks, real-time web services and others- other. The use of computers in the future will also be able to dominate human work and defeat human computing capabilities such as controlling electronic equipment remotely using internet media. IoT (Internet of Things) allows users to manage and optimize electronic equipment and electrical equipment that uses the internet. This creates the opportunity that in the near future communication of information exchange between computers and electronic equipment will reduce the amount of human interaction. This will also increase internet users with various internet facilities and services [1], [2], [3].

The main challenge in IoT is to bridge the gap between the physical world and the information world. Like how to process data obtained from electronic equipment through an interface between the user and 
the equipment. Sensors collect physical raw data from real-time scenarios and convert it into an understandable format so that it will be easily exchanged between various forms of data formats (Thing) [4].

IoT is a physical cyber system or network of networks. With the large number of things / objects and sensors or actuators that are connected to the internet, then the real-time data flow will automatically be generated in large numbers too by things that are connected with sensors [5]. All activities in the IoT are to collect the correct raw data in an efficient manner, but more important is how to analyze and process the raw data into more valuable information [1].

Internet of Things in its application can also identify, find, track, monitor objects and trigger related events automatically and in real time. The development and application of computers, the Internet and information and communication technology (ICT) has had a major impact on society's economic management, production operations, social management and even personal life [6].

The two main requirements for "Things" in IoT are sensing and addressing. Sensing is very important to identify and collect key parameters for analysis, and addressing is needed to identify unique things through the Internet. Sensors are very important in gathering key information to monitor and diagnose "Things", sensors usually do not have the ability to control or repair when repairs are needed [2]. Actuators have been introduced to answer questions about how to be able to control sensing in the IoT. With this in mind, the main requirements for "Things" in IoT now consist of sensing, actuating, and unique identification as shown in figures 1 and 2. It should be noted that the sensing ability and sensing actuating can be supported on the same device [7].

In this survey paper, the device will be used on the Internet of Things. The purpose of this survey paper is to provide insights and an overall picture of the tools used in IoT. The discussion focused on the type of IoT sensor and its characteristics, the application of RFID, video tracking, and the type of IoT actuator.

The writing consists of several parts, part I describes the introduction relating to the Internet of Things, part II describes the survey conducted related to the Internet of Things tool, part III describes the results and discussion of the survey, part IV describes the conclusions and challenges of the IoT device going forward .

\section{SURVEY}

The survey conducted focuses on research papers that discuss IoT devices, which mostly discuss sensors, RFID, and actuators.

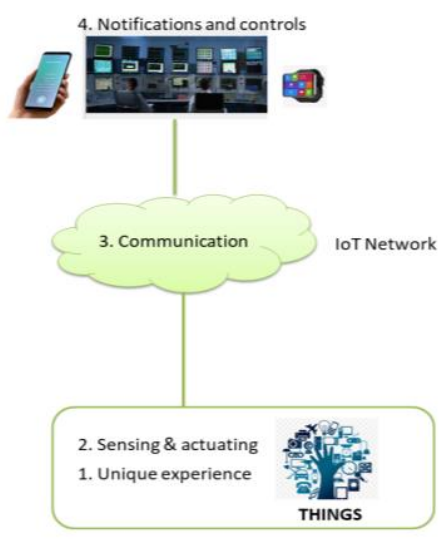

Figure 1. "Things" in IoT: definitions [7] 


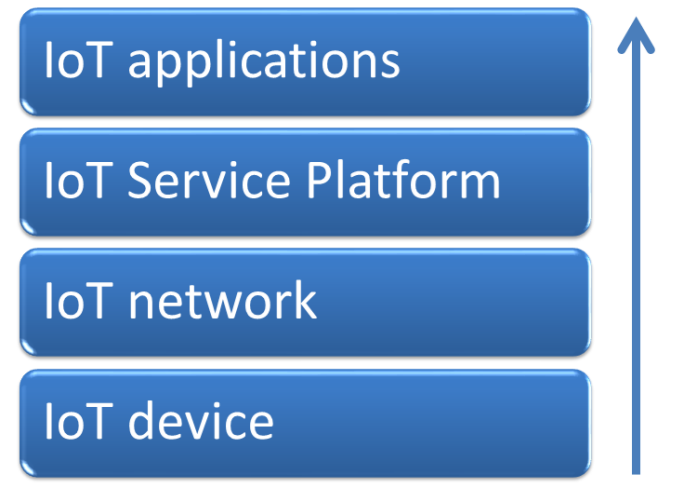

Figure 2. "Things" in IoT: intenter of things level[7]

The Internet of Things will encourage the development of a number of applications that utilize the enormous amount and variety of data generated by these objects to provide new services to citizens, companies and public administrations. This paradigm does indeed find applications in many different fields, such as home automation, industrial automation, medical assistance, mobile health care, parental assistance, smart energy management and smart networks, automotive, traffic management and others[8]

\section{RESULTS AND DISCUSSION SURVEY}

From the results of the analysis of several papers related to IoT devices, the most common and most widely used supporting components in IoT can be grouped into several physical components below:

- Sensors (sensors): to collect information.

- Identifier (identifier): to identify the source of data (e.g. sensors, devices).

- Software: to analyze data.

- Internet connectivity: to communicate and give notifications.

By combining the four components above, IoT is a network of objects with clear element identification, embedded with software intelligence, sensors, and connectivity using an Internet connection. IoT allows things or objects to exchange information with manufacturers, operators, and or other connected devices that utilize the internet telecommunications infrastructure so that physical objects provide specific information and are controlled remotely via the internet. IoT creates opportunities for more direct integration between the physical world and computer-based systems and results in increased efficiency, accuracy, and economic benefits. Everything can be uniquely identified through an embedded computing system and is able to operate within the existing internet infrastructure.

\section{A. IoT sensor}

A sensor is a device (electronic) that detects events or changes in its physical environment (for example: temperature, sound, heat, pressure, flow, magnetism, motion, chemical and biochemical parameters) and provides the appropriate output. Most sensors take analog inputs and produce digital outputs. Because the sensing element produces analog output, an analog to digital converter is often needed.

The sensor is proportional to the five human senses. They form the front end of the IoT device, "Things". Sensors are very important in every IoT role (for example: smart city, smart grid, health care, agriculture, security and environmental monitoring, and smart parking) because they can bridge the physical objects of the world with the internet. 
Sensors can be very simple with core functions to collect and transmit data by providing additional functionality to filter duplicate data and only notify the IoT gateway when very specific conditions are met. This requires some programming logic to be applied to the sensor itself. In this case, the IoT sensing device requires at least three elements - sensors, microcontrollers, and connectivity to send filtered data to the IoT gateway or other system. Figure 3. shows the components for a smart sensor [7].

Sensors can collect large amounts of data at any time and from any location and send it over the IoT network in real time. The data is then analyzed and may be correlated with other business intelligence databases to provide business insight or increase environmental awareness, bring further opportunities and / or gains in efficiency and productivity.

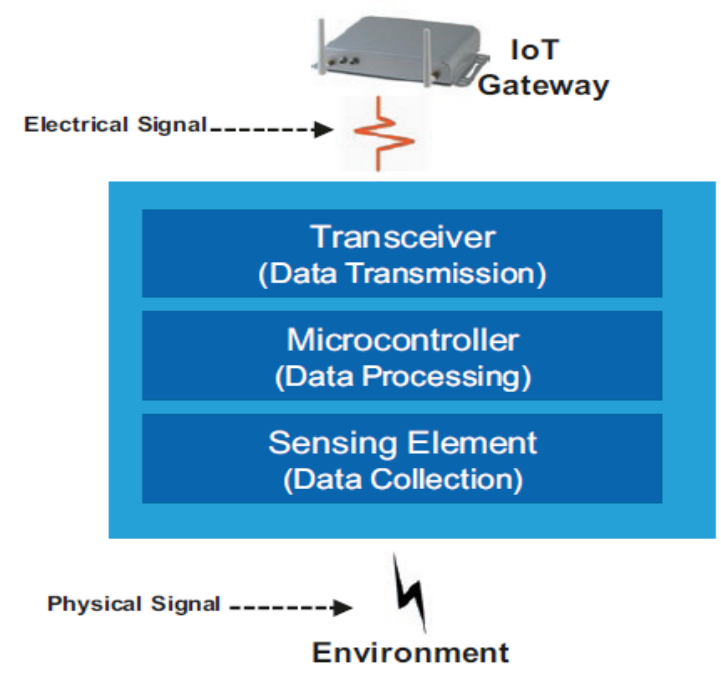

Figure 3. Smart sensor components [7]

As mentioned above, the main purpose of sensors is to collect data from the surrounding environment and provide output to adjacent devices (for example: gateways, actuators) or applications. Sensors usually collect data using a physical interface (input) that senses the environment and then converts the input signal into an electrical signal (output) that is understood by communication and computing devices. The output signal is then processed by the gateway and / or application from the IoT Platform. In some cases, sensor output is processed directly by a lightweight application.

\section{B. IoT Sensor Type}

There are many types of proprietary (patent) and non-proprietary (non-patent) sensors. The current IoT trend is to move away from patented and closed systems and embrace IP-based sensor networks. This enables tangible connectivity between wireless sensor networks and the Internet and allows smart objects to be used inside IoT [2].

IP-based sensor networks require each device to be uniquely identified with a unique IP address so that it can be easily identified over a large network. However, building all IP infrastructure from scratch will be difficult because many different sensors and actuator technologies (both wired and wireless) have been used for years.

There are many types of sensors in various technologies. The most commonly used include: 


\section{a) Temperature Sensor}

Temperature is the conservative quantity that is most often measured. This was anticipated because most physical, electronic, chemical, mechanical, and biological systems are affected by temperature [7], [8]. Table 1. summarizes the four types of temperature sensors that are commonly used.

\section{TABLE 1. TYPES OF TEMPERATURE SENSORS AND EXPLANATIONS}

\begin{tabular}{|l|l|}
\hline TYPES OF SENSOR & DESCRIPTION \\
\hline Thermocouple & $\begin{array}{l}\text { Thermocouples are devices that consist of two } \\
\text { different conductors and differ in contact. This } \\
\text { produces a voltage as a result of the thermoelectric } \\
\text { effect. Thermocouple sensors are made by } \\
\text { combining two different metals at one end. }\end{array}$ \\
\hline Resistance Temperature Detector (RTD) & $\begin{array}{l}\text { RTD is a temperature sensing device whose } \\
\text { resistance changes with temperature. RTD has been } \\
\text { used for years to measure temperature in }\end{array}$ \\
$\begin{array}{ll}\text { laboratories and industrial processes and has } \\
\text { developed a reputation for accuracy, repeatability, } \\
\text { and stability. }\end{array}$ \\
\hline Thermistor & $\begin{array}{l}\text { Similar to RTD, a thermistor is a temperature } \\
\text { sensing device that changes resistance to } \\
\text { temperature. Thermistors are made of } \\
\text { semiconductor material. Resistance is determined } \\
\text { in the same way as RT but the thermistor shows a } \\
\text { very nonlinear resistance vs. a temperature curve. }\end{array}$ \\
\hline Semiconductors & $\begin{array}{l}\text { Semiconductor temperature sensors offer high } \\
\text { accuracy and high linearity in the operating range } \\
\text { around 55 } \circ \text { C to +150 C C (-58 to 302 } \circ \text { F). } \\
\text { Semiconductors can also include signal processing } \\
\text { circuits in the same package as sensors, thereby } \\
\text { avoiding the need to add compensation circuits. }\end{array}$ \\
\hline
\end{tabular}

\section{b) Pressure Sensor}

Pressure sensors are used to measure gas or liquid pressure including water level, flow, speed, and altitude. Practical examples include sensors for pumps and compressors, hydraulic systems, and refrigerators. The pressure sensor usually acts as a transducer where it generates a signal as a function of the pressure applied [9]. Therefore, pressure sensors are often also called pressure transducers, pressure transmitters, and pressure senders.

Touch screen smartphones, tablets and computers come with various pressure sensors. Every time a slight pressure is applied to the touch screen via a finger, a small pressure sensor (usually several sensors located in the corner of the screen; see Figure 4) determines where exactly the pressure is applied and consequently produces an output signal that informs the processor. Pressure sensors have also been widely used in automotive applications to measure fluid levels, airbags, and anti-lock braking systems, in biomedical applications to measure blood pressure, in flight to maintain a balance between atmospheric pressure and aircraft control systems, and in submarines to estimate depth and ensure proper operation of electronic systems and other components. Figure 4 shows an example of a pressure sensor. 

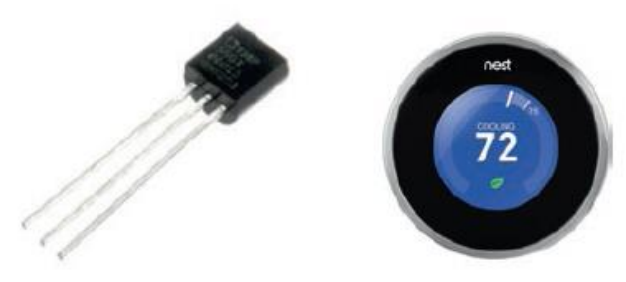

Figure 3. Example of a temperature sensor[7]

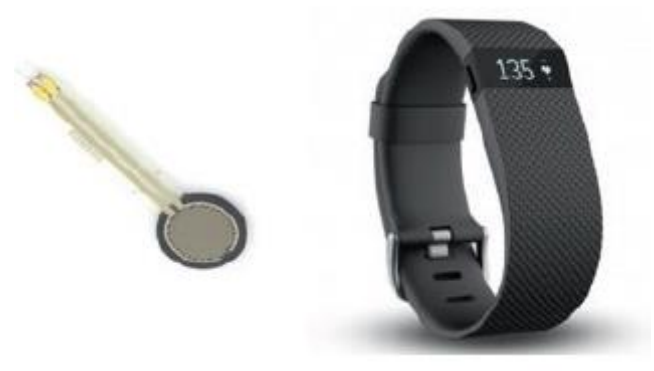

Figure 4. Examples of pressure sensors (source: Force Sensing \& Fitbit)

c) Flow Sensor

Flow sensors are used to detect and record fluid flow rates in a pipe or system. Flow sensors can also be used to measure the flow / heat transfer caused by moving media. Feeling and measuring flow is very important for many applications down to more serious applications such as flow monitoring for high purity acids and others.

A good example of the importance of flow sensing and monitoring is the water crisis in Flint, Michigan, United States, which began in April 2014 and resulted in criminal charges by the Michigan Attorney General in April 2016 against three people in connection with the water crisis [7].

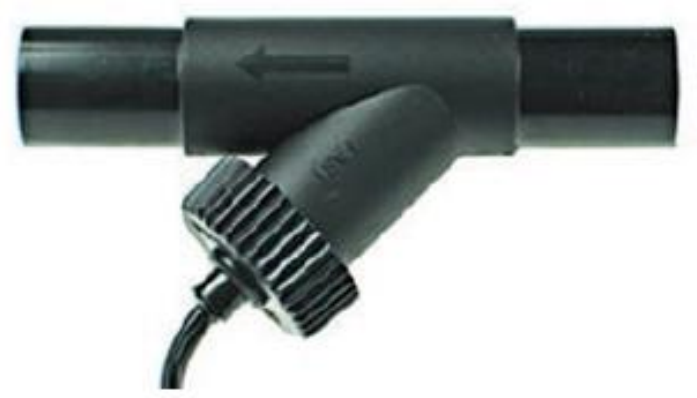

Figure 5. Example of flow sensor[7] 

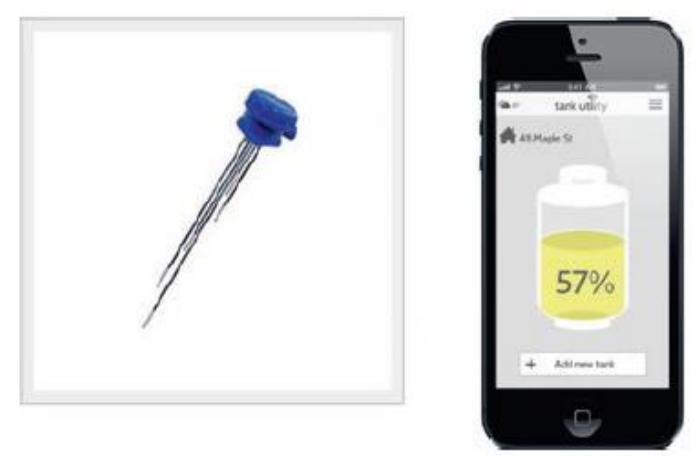

Figure 6. Example of a level sensor with remote monitoring of propane Wi-Fi. (Source: Tank Utility)

\section{d) Level Sensor}

Level sensors are used to measure fluid levels continuously or at a certain point value [8]. The element to be measured can be in a container (Figure 6) or it can be in a natural form such as a well or a fluid reservoir [10].

There are many uses of level sensors. For example, ultrasonic level sensors are used for sensing noncontact levels of very thick liquids and even large amounts of solid material. Level sensors are also widely used in water treatment applications for pump control and measurement of open channel flow [10]. Another example is the level sensor to measure the capacity of the presence of solid and liquid objects using radio frequency signals.

\section{e) Imaging Sensors}

Imaging sensors are sophisticated sensors used in digital cameras, medical imaging machines, and night vision equipment. Imaging sensors are used to measure image information by capturing and then changing the wave attenuation variable into a signal [2].

\section{f) Noise Sensor}

High noise can have deleterious effects on humans (e.g. Cardiovascular) as well as animals (e.g. Hearing loss). Such noise is often caused by engines, airplanes, trains, construction, and loud music especially in confined spaces.

Many government agencies have begun installing noise sensors to measure noise pollution or noise interference (excessive noise that can harm humans or animals).

The noise sensor continuously monitors the noise level in the surrounding environment. When the noise level changes, the noise sensor sends an electronic signal to the entire surrounding noise system to take action. The action can be an automatic action (e.g. adjusting the volume of music) or simple notification to the authorities.

\section{g) Air Pollution Sensor}

Many governments have formed institutions to monitor and control air quality in big cities. For example, the United States established the EPA (Environmental Protection Agency) in 1970 with a mission to protect Americans from significant health risks by providing accurate environmental information to their citizens. 
The air pollution sensor detects and monitors the presence of air pollution in the surrounding environment. They focus on five main components namely: ozone, particles, carbon monoxide, sulfur dioxide, and nitrous oxide [9], [8].

h) Proximity and Displacement Sensors

Proximity sensors detect the presence or absence of objects using electromagnetic fields, light, or sound [9], [8]. There are many types of proximity and displacement sensors, each suitable for a specific application and environment as summarized in Table 2.

\section{TABLE 2. TYPES OF DISTANCE SENSORS}

\begin{tabular}{|l|l|l|}
\hline Sensor Technology & Sensing Range & Function \\
\hline Inductive & $4-40 \mathrm{~mm}$ & $\begin{array}{l}\text { Iron metal melee detection (e.g. } \\
\text { Iron, aluminum, copper) }\end{array}$ \\
\hline Capacitive & $3-60 \mathrm{~mm}$ & $\begin{array}{l}\text { Short range detection of non- } \\
\text { ferrous materials (eg wood, } \\
\text { plastic liquids) }\end{array}$ \\
\hline Photoelectrical & $\begin{array}{l}\text { Detect material remote targets } \\
\text { Ultrasonic }\end{array}$ & $\begin{array}{l}\text { Remote detection of challenging } \\
\text { material targets (e.g., rough } \\
\text { service, various colors) }\end{array}$ \\
\hline
\end{tabular}

Examples of the application of proximity and displacement sensors can be used in the case of safety systems for vehicle tracking [11].

i) Infrared Sensor

Infrared sensors are used to track the movement of an object. This sensor generates and receives infrared waves in the form of heat [8].

\section{j) Humidity Sensor}

Humidity sensors (sometimes referred to as hygrometer sensors) are used to measure and inform the relative humidity of air [8]. This sensor uses capacitive measurements by relying on electrical capacitance.

\section{k) Speed Sensor}

Speed sensors are usually used to detect the speed of a transport vehicle. Examples include wheel speed sensors, speedometer, radar doppler, and laser surface velocimeter.

Speed sensors can also be used to detect and collect traffic data for each vehicle on the road. Vehicle detection is achieved by using an inductive loop detector. Data from this sensor will then be transferred and analyzed for example for the purposes of traffic management systems [12].

1) Gas and Chemical Sensors 
Gas and chemical sensors are intended to detect volatile compounds. Gas and chemical sensors play an important role in many applications, and have been widely developed over the past several decades. This is especially true for applications in monitoring automotive exhaust, monitoring air quality, and wastewater management [10], [13].

\section{m) Energy Consumption Monitoring Sensors}

Energy monitoring devices integrated with the concept of the Internet of Things enable energy usage data to be monitored and retrieved at any location where the internet is available. An electrical / energy consumption sensor was developed to measure voltage, current, power, and energy from a four-phase or three-phase power line somewhere such as a house, building or building. This sensor can be integrated with a microcontroller, and serial-to-wifi module for communication. The use of these sensors properly provides enormous benefits to support energy management that is efficient in business processes and costs because it can produce reliable and smooth data [14], [15].

\section{Characteristics of Internet of Things Sensors}

Most Internet of Things (IoT) applications require smaller and smarter sensors with sophisticated functions to collect more data, lower power processors, longer battery life, faster response times, and shorter marketing times. Sensors are expected to be dynamic in their natural environment with embedded capabilities to collect real time data [15].

In general, sensors can be directed autonomously so that they can work alone after they are installed or controlled by users where the conditions have been pre-programmed by users according to their needs [15]. Ultimately, the sensor must have the ability to send data collected to the appropriate system through the IoT gateway as illustrated in Figure 2. The IoT sensor is expected to have the following characteristics:

\section{1) Filtering data}

The core function of a sensor is its ability to collect and send data to an IoT gateway or other suitable system. Sensors are not expected to perform deep analytical functions. However, a simple screening technique might be needed. Onboard data (or signals) processing a microcontroller (as shown in Figure 3) makes smart sensors smarter. The microcontroller filters the data / signal before it is sent to the IoT gateway or control network [2]. The filtering function basically removes duplicate or unwanted data or noise before transferring data [3].

\section{2) Minimum power consumption}

Several factors drive the requirements for low power consumption in IoT [15], [16], [17], [18]. Sensors for some examples of IoT environments such as smart grids [19], railroad tracks, and road sides are installed in locations that are difficult to reach to replace batteries.

\section{3) Compact (compact)}

Space will also be limited for most IoT devices. Thus, the sensor must fit and can be placed in a small space [7].

\section{4) Smart detection}

Remote sensing is an important sensing category for IoT which consists of obtaining information about an object without making physical contact with it. it could be nearby or several hundred meters away [20]. 
Several technology options are available for remote sensing, and they can be divided into three major functions namely:

- Detect presence or distance, when only determining the presence or absence of an object can be used for example security applications. This is the simplest form of remote sensing [8].

- Speed measurement, when the exact position of an object is not needed, but only for accurate speed measurement the traffic monitoring application can be used.

- Detection and range, when the position of the object relative to the sensor must be determined precisely and accurately, for example avoiding vehicle collisions.

5) High sensitivity

Sensitivity in general is the ratio between small changes in the electrical output signal and small changes in physical signals. It can also be expressed as a derivative of the transfer function (the functional relationship between the input signal and the output signal) with respect to the physical signal. Sensitivity shows how much the device's output changes with changes in input units (the quantity to be measured) [3].

\section{6) Linearity}

Linearity is a measure of the degree to which output is linearly proportional to output. Nonlinear is the maximum deviation of the linear transfer function in the specified dynamic range [7].

7) Dynamic range

The range of input signals that can be converted into electrical signals by sensors. Outside the range of this signal causes unsatisfactory accuracy [7].

\section{8) Accuracy}

The maximum expected error between measured (actual) and ideal output signals. Manufacturers often provide accuracy in data sheets, for example high-quality thermometers may list accuracy of up to $0.01 \%$ of full-scale output [17].

9) Hysteresis

When a sensor does not return the same output value when the input stimulus is pushed up or down. The width of the expected error in terms of the measured quantity is defined as hysteresis [7].

10) Limited Interference

All sensors produce a level of traffic interference with the output signal. Sensor interference is only a problem if it impacts the performance of the IoT system. Smart sensors must filter unwanted disturbances and be programmed to produce warnings when critical limits are reached. Disturbances are generally distributed across the frequency spectrum [17].

11) Wide bandwidth 
The sensor has a response time to sudden changes in physical signals. Many sensors have a decay time, i.e. the time of changing the input signal to the sensor output decays to its original value. The bandwidth of a sensor is the range of frequencies between these two frequencies. When sensors are used to collect measurements, it is recommended to use sensors with the widest possible bandwidth to ensure that the basic measurement system is able to respond linearly as needed. The disadvantage is that wider bandwidth can cause the sensor to respond to unwanted frequencies.

\section{2) High resolution}

Sensor resolution is defined as the smallest signal fluctuation detected. Resolution is the smallest change in input that can be detected by the device. The definition of resolution must include some information about the nature of the measurements taken [7].

\section{2) High resolution}

Sensor resolution is defined as the smallest signal fluctuation detected. Resolution is the smallest change in input that can be detected by the device. The definition of resolution must include some information about the nature of the measurements taken [7].

\section{3) Minor annoyances}

The sensor must operate normally at all times with zero or near zero interference and be programmed to generate its own warning when operation is interrupted [15].

14) High reliability

Sensors with higher reliability provide guarantees in terms of the accuracy of the output measurements [3].

\section{5) Ease of use}

Ease of use is considered a key requirement for any electronic system at this time is no exception to the IoT driver [15]. A clear example that we have all experienced is the iPhone vs Apple device from competitors with the same functionality. Users are willing to pay more for devices that are easy to use and the sensor is no exception. The best user interface is "no user interface" where sensors are expected to work alone once they are connected.

\section{RFID}

Another way to get information from "Things" is through the use of RFID (radio-frequency identification). RFID is not a sensor but a mechanism to capture information that has been embedded into what is called a "tag" of something or an object that uses radio waves [5]. RFID consists of two parts: one tag and one reader. Furthermore, tags have two parts: a microchip that stores and processes information and an antenna to receive and transmit signals. The tag contains a specific serial number for one particular object. The reader reads the information encoded in a tag, using a two-way radio receiver by emitting signals to the tag using an antenna. The tag responds with information written in its memory. The reader will then send the reading results to the RFID computer program. Figure 7 shows the main components of RFID.

RFID based solutions have advantages and disadvantages. Table 3 summarizes these advantages and disadvantages [7][8]. 


\begin{tabular}{|c|c|}
\hline Advantages of RFID & Lack of RFID \\
\hline $\begin{array}{l}\text { - RFID tags can be read from distances of up } \\
\text { to } 12 \mathrm{~m} \text { for passive UHF systems. Battery } \\
\text { powered tags usually have a reading range } \\
\text { of } 100 \mathrm{~m} \text {. } \\
\text { - RFID data on tags can be modified based } \\
\text { on business needs. Barcode data is very } \\
\text { difficult to change after use. } \\
\text { - Durable RFID Tag. Barcodes, by } \\
\text { comparison, are printed on a product for } \\
\text { everyone to see. They can be damaged or } \\
\text { changed. RFID tags are hidden and can be } \\
\text { reused in many products. RFID tags are } \\
\text { also capable of storing more data. } \\
\text { RFID data can be encrypted on tags, } \\
\text { thereby preventing unauthorized users from } \\
\text { changing data or forgery. } \\
\text { RFID systems can read hundreds of tags } \\
\text { simultaneously. This is important in retail } \\
\text { stores because it saves valuable staff time } \\
\text { that they can spend on higher-value tasks. }\end{array}$ & $\begin{array}{l}\text { - Vulnerable to interference with RFID radio } \\
\text { waves } \\
\text { Interference / interference between } \\
\text { multiple readers and tags if the whole } \\
\text { system is not set correctly }\end{array}$ \\
\hline
\end{tabular}

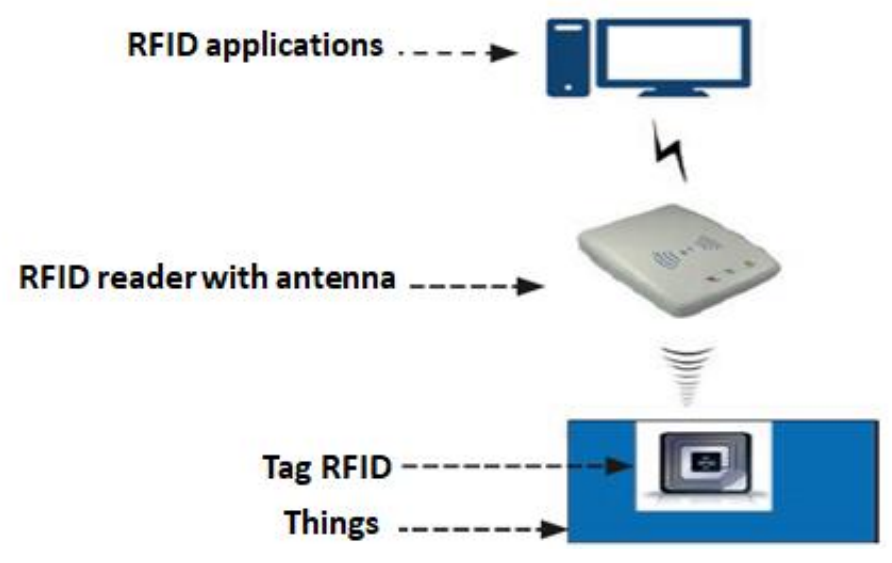

Figure 7. The main components of RFID[7]

RFID has been widely used by a large number of applications including:

- Access control and management, used within companies or governments to identify replacing magnetic stripe cards that were used previously.

- Collection of electronic information on toll roads to eliminate delays on toll roads

- Passports, many state departments around the world (for example the United States, Canada, Norway, Malaysia, Japan, and European Union countries) use RFID passports that can be read from readers up to $10 \mathrm{~m}$ away.

- Health services, implementing RFID in hospitals to improve health services.

- Logistics and Supply Chain Tracking, many factories track their products during the manufacturing process using RFID to estimate customer delivery dates better. 
- Timing Athletic and Sports Games, RFID tracks the exact time of a marathon or race runner whose time difference is often a fraction of a second.

- Animal tracking, since outbreaks of mad cow disease, RFID has become important in the management of animal identification, although RFID animal tagging began at least a decade before the disease.

- Other applications, RFID is also used for airport baggage tracking logistics, interactive marketing, item inventory tracking, conference participant tracking, material management, IT asset management, library systems, and real time location systems.

\section{E. Video Tracking}

Video tracking is the process of capturing and analyzing video data frame by frame of a particular object or person in a short time interval. Video tracking is used to measure and analyze motion, visual attention, and behavior. Video tracking is used for customer identification, surveillance, augmented reality, traffic control, and medical imaging [12].

Video tracking is another mechanism for identifying and monitoring "Things" when RFID sensors or tags are not available. Video tracking can also be used in conjunction with sensors and or RFID to provide a more comprehensive solution.

Video tracking has a number of drawbacks when it comes to current technology: often time consuming, careful analysis is needed to get an accurate conclusion. Another challenge for video tracking is complex object / image recognition techniques.

\section{F. IoT Actuators}

An actuator is a type of motor that is responsible for controlling or taking action in a system. It takes a data source or energy (for example: hydraulic fluid pressure or other resources) and converts data / energy into motion to control a system [7].

Sensors are responsible for sensing changes around them (sensing), collecting relevant data, and making that data available for monitoring systems. Collecting and displaying data with a monitoring system is useless unless the data is translated into intelligence which can be used to control or manage an environment before a service is affected. Actuators use data collected by sensors and analyzed to control the IoT system. For example, turning off the gas flow when the pressure measured is below a certain threshold.

The type of actuator commonly used in IoT is explained in the section below.

\section{1) Electric actuators}

An electric actuator is a device that is driven by a small motor that converts energy into mechanical torque. The torque made is used to control certain equipment that requires a multi-rotation valve or to control the gate. Electric actuators are also used in engines to control various valves.

\section{2) Mechanical linear actuators}

Mechanical actuators convert rotary motion into linear motion. Devices such as screws and chains are used in this conversion. The simplest example of a mechanical linear actuator is called a "screw" in which the opening screw, screw jack, ball screw and roller screw actuator all operate on the same principle by turning the actuator nut, the screw shaft moves in a line. Figure 9 shows an example of a screw jack. 


\section{3) Hydraulic actuators}

Hydraulic actuators are simple devices with mechanical parts used on linear valves or quarter turns. Hydraulic actuators are designed according to Pascal's Law: when there is an increase in pressure at any point in a liquid that cannot be compressed, then there is an equal increase at every point in the container [7].

Hydraulic actuators can be operated manually, such as a hydraulic car jack, or can be operated via a hydraulic pump, which can be seen on construction equipment such as cranes or excavators.

\section{4) Pneumatic Actuators}

Pneumatic actuators work with the same concept as hydraulic actuators except compressed gases are used instead of liquids [7].

5) Manual Actuators

Manual actuators use levers, gears, or wheels to allow movement, while automatic actuators have an external power source to provide movement to operate the valve automatically [7].

There are two control approaches that can be used to monitor and control IoT devices, namely local control and global control. The first approach requires intelligent local controllers (such as home thermostats to control the furnace and air conditioning system). The second approach is to move controls to the cloud and simply embed inexpensive sensors everywhere (eg the thermostat is completely removed) by placing a temperature sensor around the house [7].

The easiest way to identify each IoT device is to assign a unique IP address for each sensor and actuator. However, IPv4 addresses are expensive and limited. IPv6 addresses are not widely used yet. In addition, many sensors and actuators do not activate IP. The IoT Gateway has a unique IP address. Therefore, sensors and actuators that do not support IP can be identified by the relevant gateway.

\section{CONCLUSIONS AND CHALLENGES FORWARD}

Three main techniques for identifying things in IoT have been discussed in detail including embedded hardware sensors that sensing objects around them and notifying client applications, RFID with tags to store information about something and reader to read the information and forward it to the application for analysis. After the data is analyzed (from sensors or other sources), the IoT actuator is responsible for controlling or taking action if needed. Finally, the procedure has been discussed to identify various devices in the IoT network.

Future challenges regarding IoT devices that still exist and have broad opportunities to be investigated include issues related to the integration of hardware and software from several different vendors, interactions with devices using several wireless protocols, data collection real-time and analytic data, problems with a safe and seamless connection to the cloud, issues of design and deployment of IoT devices, remote device management and diagnosis, and IoT development tools. 


\section{REFERENCE}

[1] C. Wang, M. Daneshmand, M. Dohler, X. Mao, R. Q. Hu, and H. Wang, "Guest Editorial Special Issue on Internet of Things (IoT): Architecture, Protocols and Services," IEEE Sens. J., vol. 13, no. 10 , pp. 3505-3510, 2013.

[2] T. Adegbija, A. Rogacs, C. Patel, and A. Gordon-ross, "Microprocessor Optimizations for the Internet of Things : A Survey," IEEE Trans. Comput. Des. Integr. Circuits Syst., vol. 37, no. 1, pp. 7-20, 2018.

[3] A. H. Ngu, M. Gutierrez, V. Metsis, and Q. Z. Sheng, "IoT Middleware : A Survey on Issues and Enabling Technologies," IEEE Internet Things J., vol. 4, no. 1, pp. 1-20, 2017.

[4] P. Suresh, J. V. Daniel, V. Parthasarathy, and R. H. Aswathy, "A state of the art review on the Internet of Things ( IoT ) History, Technology and fields of deployment," 2014 Int. Conf. Sci. Eng. Manag. Res., pp. 1-8, 2014.

[5] O. Bello, S. Zeadally, and S. Member, "Intelligent Device-to-Device Communication in the Internet of Things," IEEE Syst. J., vol. 10, no. 3, pp. 1172-1182, 2016.

[6] Q. Zhou and J. Zhang, "Review and Prospect," 2011 Int. Conf. Multimed. Signal Process., vol. 2, pp. 47-51, 2011.

[7] A. Rayes and S. Salam, "Internet of Things From Hype to Reality," Second Ed., Springer Nature Switzerland, 2019, pp. 67-88.

[8] Y. Marine and S. Saluky, "Penerapan IoT untuk Kota Cerdas", itej, vol. 3, no. 1, pp. 36 - 47, Jul. 2018.

[9] Y. Lin, Y. Lin, C. Huang, C. Chih, and P. Lin, "IoTtalk: A Management Platform for Reconfigurable Sensor Devices," IEEE INTERNET THINGS J., vol. 4, no. 5, pp. 1552-1562, 2017.

[10] M. Soprani, G. Duina, M. Malgaretti, M. Abbatangelo, and V. Sberveglieri, "Array of Semiconductor Nanowires Gas Sensor for IoT in Wastewater Management," pp. 68-71, 2018.

[11] M. Saegusa and K. Katsura, "Development of a smart IoT device for Bicyclists," Int. Conf. Integr. Circuit, Des. Verif., no. Icdv, pp. 64-68, 2017.

[12] H. F. Chong, D. Wee, and K. Ng, "Development of IoT Device for Traffic Management System," 2016 IEEE Student Conf. Res. Dev., pp. 1-6, 2016.

[13] M. Ito, N. Nishinaga, Y. Kitatsuji, and M. Murata, "Reducing State Information by Sharing IMSI for Cellular IoT Devices," IEEE Internet Things J., vol. 3, no. 6, pp. 1297-1309, 2016.

[14] S. Wasoontarajaroen, K. Pawasan, and V. Chamnanphrai, "Development of an IoT Device for Monitoring Electrical Energy Consumption," Int. Conf. Inf. Technol. Electr. Eng., pp. 1-4, 2017.

[15] V. Mattela, "IoT Device Development Challenges and Solutions," 2015 IEEE Hot Chips 27 Symp., pp. 1-19, 2018.

[16] T. Wan, Y. Karimi, and M. Stana, "Perspective Paper - Can AC Computing Be an Alternative for Wirelessly Powered IoT Devices ?,” IEEE Embed. Syst. Lett., vol. 9, no. 1, pp. 13-16, 2017.

[17] H. Sedjelmaci and S. M. Senouci, "An Accurate Security Game for Low-Resource IoT Devices," IEEE Trans. Veh. Technol., vol. 66, no. 10, pp. 9381-9393, 2017.

[18] S. Ma, Q. Liu, and P. C. Sheu, "Foglight: Visible Light-Enabled Indoor Localization System for Low-Power IoT Devices," IEEE Internet Things J., vol. 5, no. 1, pp. 175-185, 2018. 